\title{
sciforum
}

Conference Proceedings Paper

\section{Extreme drought events over the Amazon basin: The perspective from the reconstruction of South American hydroclimate}

\author{
Beatriz N. Garcia ${ }^{1}$, Renata Libonati1,* and Ana Nunes ${ }^{1}$ \\ Published: 11/11/2017 \\ Academic Editor: José Marengo \\ 1 Departamento de Meteorologia, Instituto de Geociências, Universidade Federal do Rio de Janeiro, Brazil; \\ beatrizngarcia@ufrj.br; renata.libonati@igeo.ufrj.br; ana.nunes@igeo.ufrj.br \\ * Correspondence: renata.libonati@igeo.ufrj.br; Tel.: +55-21-39389470
}

\begin{abstract}
In less than two decades large areas of the Amazon Basin have experienced severe droughts, namely during 1998, 2005, 2010 and 2015. Due to their several social, economic and environmental impacts there is an increased demand in understanding the behavior of such extreme events in the region. In that regard, regional models instead of the general circulation models provide a promising strategy to generate more detailed climate information of extreme events, seeking better representation of physical processes. In such context, the Satellite-enhanced Regional Downscaling for Applied Studies (SRDAS) product has been used in the analysis of South American hydroclimate, with hourly to monthly outputs from January 1998 to near present. Accordingly, this research focuses on the analyses of recent extreme drought events in the years of 2005 and 2010 in the Amazon Basin, using the SRDAS monthly means of near-surface temperature and relative humidity, precipitation and four-level integrated soil moisture fields. Results from this analysis corroborate spatial and temporal patterns found in previous studies on extreme drought events in the region, displaying the distinctive features of the 2005 and 2010 drought events.
\end{abstract}

Keywords: extreme event; downscaling; precipitation assimilation; hydro-climatology

\section{Introduction}

Extreme drought events have occurred in the Amazon basin for thousand years [1], and several of these historical events since last century, as in 1906, 1912, 1916, 1925, 1936, 1948, 1957/58, 1963/64; 1970; 1982/83, 1987, 1997/98, 2005, 2010 and 2015 [2-6]. It was also detected that these events were more frequently in the past decades, as well as more intense [1]. Each extreme drought event of the $21^{\text {st }}$ century was considered more powerful than the last one [6].

Drought events in the Amazon are associated with teleconnections due to El-Niño Southern Oscillation and/or anomalous heating of North Atlantic sea surface temperature (SST). The 2005 event was related to the elevated warming in the north Atlantic SST and its epicenter was in the west of the basin. In contrast, the 2010 event was related to both teleconnections and had three different epicenters: west, northwest and southeast areas.

Both general circulation and regional models have improved in recent years in terms of depiction of processes and phenomena to address impacts of global climate change. Part of this breakthrough comes from increased spatial resolution and part comes from the inclusion of climate controls from new system components and their interaction. The use of regional downscaling of general circulation models provides a technique to generate more refined climatic information on extreme events through better representation of physical processes [7]. 
The 1st International Electronic Conference on Hydrological Cycle (CHyCle-2017), 12 -16 November 2017; Sciforum Electronic Conference Series, Vol. 1, 2017

\section{Materials and Methods}

SRDAS is available in South American domain $\left(93.6^{\circ} \mathrm{W}-25.8^{\circ} \mathrm{W}\right.$ and $\left.20.4^{\circ} \mathrm{S}-42.6^{\circ} \mathrm{S}\right)$, with initial condition on 1 January 1998 at 0000 UTC, and hourly outputs available from 1000hPa to $10 \mathrm{hPa}$ levels and horizontal resolution of about $25 \mathrm{~km}$. It relies on a Regional Spectral Model integration that uses newly updated version of scale-selective bias correction and precipitation assimilation [7]. For this study, monthly means of precipitation, 2-m above the ground air temperature and relative humidity, and four-level integrated soil moisture from SRDAS are used from January 1998 to December 2012 in the region of $80^{\circ} \mathrm{W}-51^{\circ} \mathrm{W}$ and $6^{\circ} \mathrm{N}-21^{\circ} \mathrm{S}$. These monthly means are used to calculate the spatial distribution of the anomalies over the Amazon basin, and time series of 3-month running mean of the SRDAS anomalies. The month that better represents each drought event, as captured by the station data, was chosen to be analyzed in this study through the SRDAS product. In both drought events that month was September.

Observational monthly precipitation and temperature fields are used together with the SRDAS product in the analyses of the two drought events. The datasets are from Instituto Nacional de Meteorologia (INMET) and Instituto de Controle do Espaço Aéreo (ICEA). Meteorological stations located near the epicenters of each one of the droughts are used in the analyses, they are: the INMET's Cruzeiro do Sul station $\left(72.66^{\circ} \mathrm{W} ; 7.6^{\circ} \mathrm{S}\right)$, used in the characterization of the 2005 drought, within the time interval 1962-2015; and the ICEA's Vilhena station $\left(60.1^{\circ} \mathrm{W} ; 12.7^{\circ} \mathrm{S}\right)$, selected for the analysis of the southeastern epicenter of the 2010 drought, considering the data availability from 1975 to 2015.

The $10^{\text {th }}, 50^{\text {th }}$ and $90^{\text {th }}$ percentiles of both time series are calculated using station data, to analyze how both years of extreme drought behave during each month of the year, especially during the Amazon basin's drought season from June to September (JJAS).

\section{Results and Discussion}

\subsection{Annual Cycle of Precipitation and Temperature: Observations and Extremes}

The 2005 and 2010 droughts in the Amazon basin were characterized using the temperature and precipitation annual cycles from the two available stations located near the epicenter of each drought as reported in previous studies (Figure 1). Cruzeiro do Sul registered increase in temperature values for the 2005 event (blue curve), showing values above the $50^{\text {th }}$ percentile from the annual cycle and, considering only the drought season, values slightly above the $90^{\text {th }}$ percentile in August (Figure 1a). During the 2005 event, precipitation was maintained near the $10^{\text {th }}$ percentile from June to August, and dropped below that value in September (Figure 1a). For the 2010 event (red curve), the station located in Vilhena registered temperature values near the $50^{\text {th }}$ percentile, except for September, with maximum in temperature reaching the $90^{\text {th }}$ percentile (Figure $1 \mathrm{~b}$ ); and precipitation near zero over most of the drought season (Figure 1b). 
The 1st International Electronic Conference on Hydrological Cycle (CHyCle-2017), 12 -16 November 2017; Sciforum Electronic Conference Series, Vol. 1, 2017

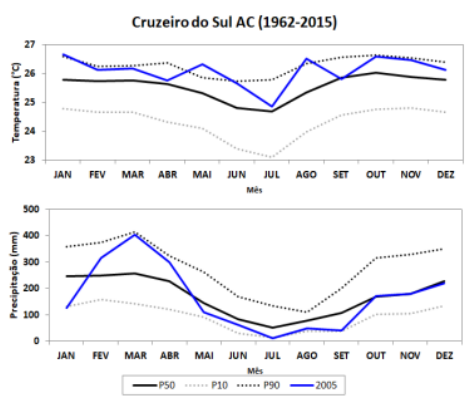

(a)

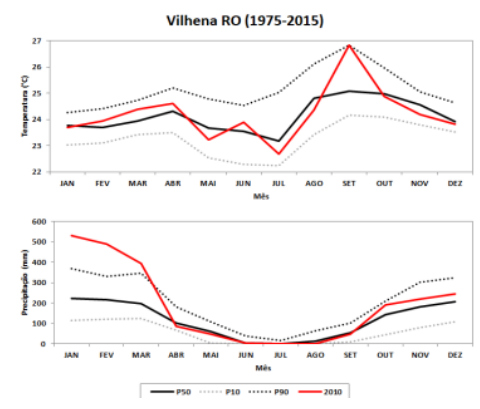

(b)

Figure 1. P50, P10 and P90 $\left(50^{\text {th }}, 10^{\text {th }}\right.$ and $90^{\text {th }}$ percentile, respectively) for temperature $\left({ }^{\circ} \mathrm{C}\right)$ and precipitation (mm) annual cycles, displaying stations values of: (a) Cruzeiro do Sul, AC, base period 1962-2015, and the year of 2005 (blue curve); (b) Vilhena, RO, base period 1975-2015, and the year of 2010 (red curve).

\subsection{Near- and Surface Variables: SRDAS}

The inspection of the SRDAS anomaly time series, areal averaged over most of the Amazon basin, exhibits anomalous features in JJAS for the years of 2005 and 2010 that are compatible with dry conditions for that region. The precipitation, 2-m relative humidity and integrated soil moisture curves show negative anomalies, and the $2-\mathrm{m}$ temperature has positive monthly anomalies in the drought season in both years (Figure 2a-d). However, soil moisture anomalies seem to better assess the 2005 and 2010 drought events (Figure 2d), especially in comparison with the SRDAS anomaly values for precipitation (Figure 2a).

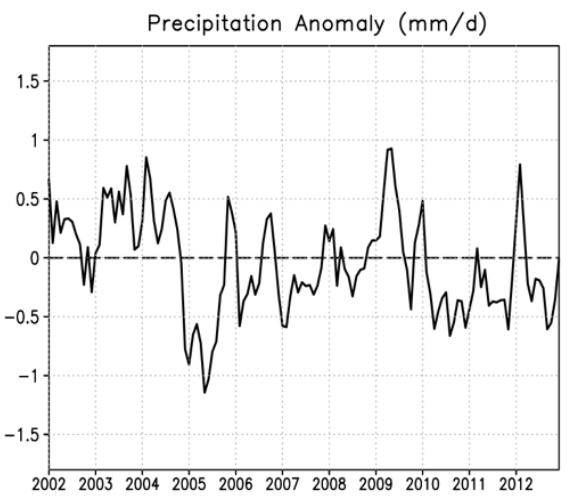

(a)

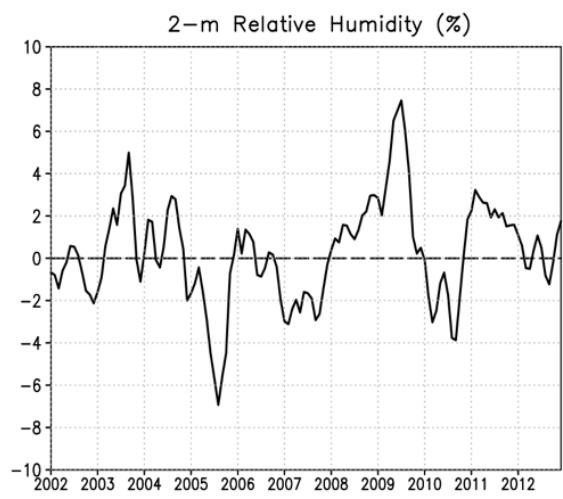

(c)

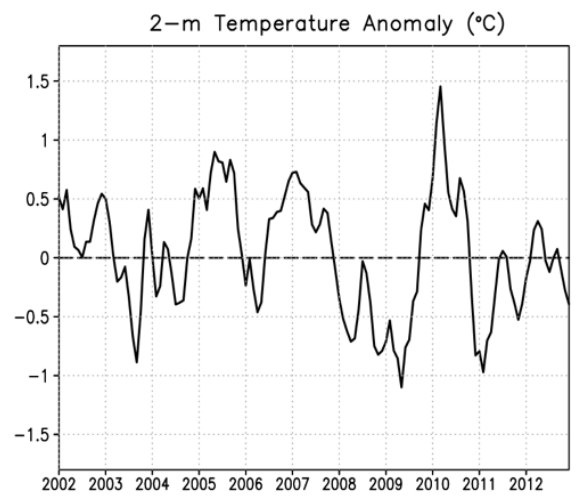

(b)

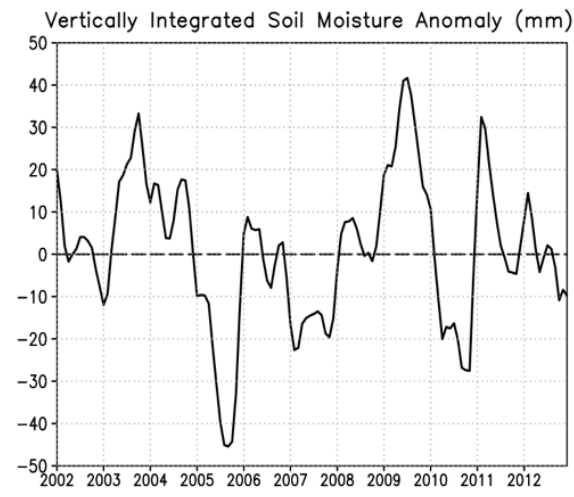

(d)

Figure 2. 3-month running mean of the SRDAS anomaly fields, averaged over the Amazon basin: (a) Precipitation $(\mathrm{mm} / \mathrm{d})$; (b) 2-m above ground temperature $\left({ }^{\circ} \mathrm{C}\right) ;(\mathrm{c}) 2-\mathrm{m}$ above ground relative humidity $(\%)$; (d) four-level integrated soil moisture (mm). Base period 1998-2012. 
The 1st International Electronic Conference on Hydrological Cycle (CHyCle-2017), 12 -16 November 2017; Sciforum Electronic Conference Series, Vol. 1, 2017

The spatial distribution of the SRDAS anomaly fields in the Amazon basin displays the anomalous negative patterns of precipitation and four-level integrated soil moisture displaced to the western area (Figures 3a and 3d), and anomalously positive near-surface (2-m above the ground) temperature values spread over the northern (Figure $3 b$ ), and negative anomalies of near-surface relative humidity mostly in the western and central areas of the river basin in September of 2005 (Figure 3c).

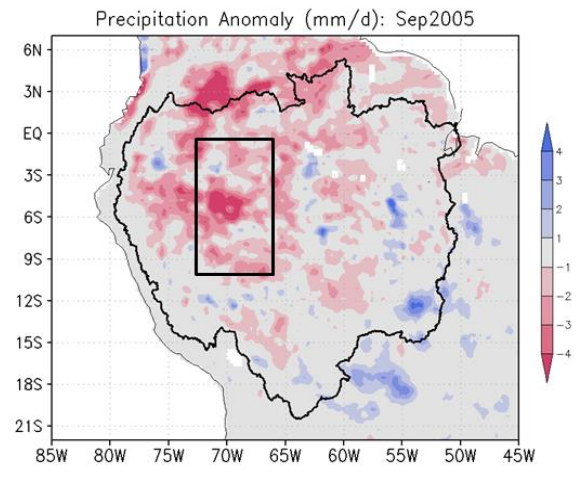

(a)

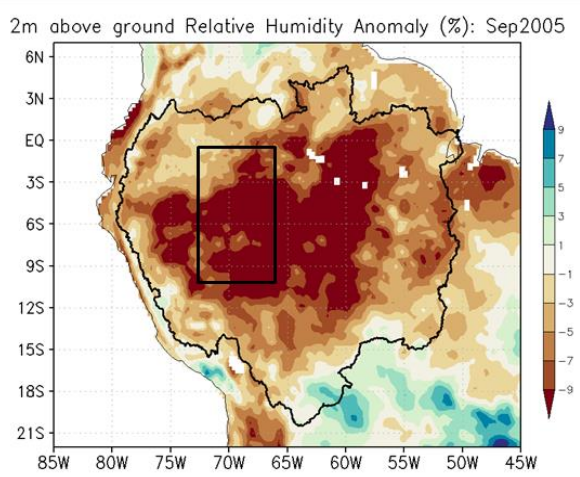

(c)

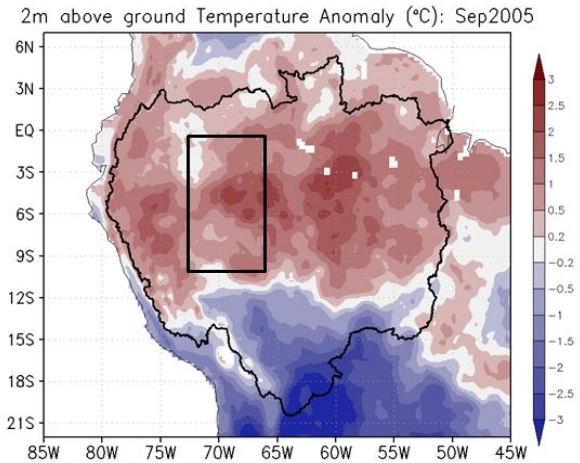

(b)

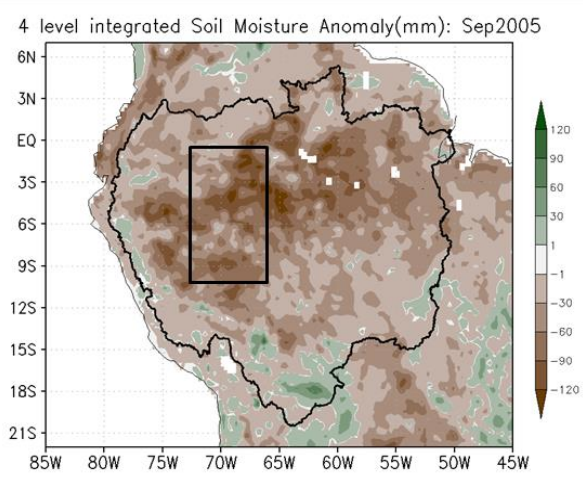

(d)

Figure 3. SRDAS anomaly fields of monthly mean for September 2005: (a) Precipitation (mm/d); (b) 2-m above ground temperature $\left({ }^{\circ} \mathrm{C}\right)$; (c) 2-m above ground relative humidity $(\%)$; (d) four-level integrated soil moisture ( $\mathrm{mm}$ ). The black contour encompasses the Amazon basin, with a black box indicating the epicenter region.

For the 2010 event, the spatial distribution of the SRDAS anomaly fields exhibits negative patterns of precipitation and integrated soil moisture over most of the Amazon basin (Figures 4a and $4 \mathrm{~d}$ ), and anomalously positive near-surface temperature values concentrate in the southeastern part of the river basin (Figure $4 \mathrm{~b}$ ), as well as the negative anomalous values of near-surface relative humidity (Figure 4c), in agreement with [6] results.

The location and intensity of the 2005 and 2010 drought events in SRDAS agree with past studies, and might demonstrate the feasibility of regional reconstructions based on the downscaling of global reanalysis fields, using a combination of boundary forcing procedures, such as assimilation of satellite-based precipitation estimates and scale-selective bias correction. That blend of techniques might be responsible to maintain the large-scale information into the regional model domain in climate integrations, including drought episodes 
The 1st International Electronic Conference on Hydrological Cycle (CHyCle-2017), 12 -16 November 2017; Sciforum Electronic Conference Series, Vol. 1, 2017

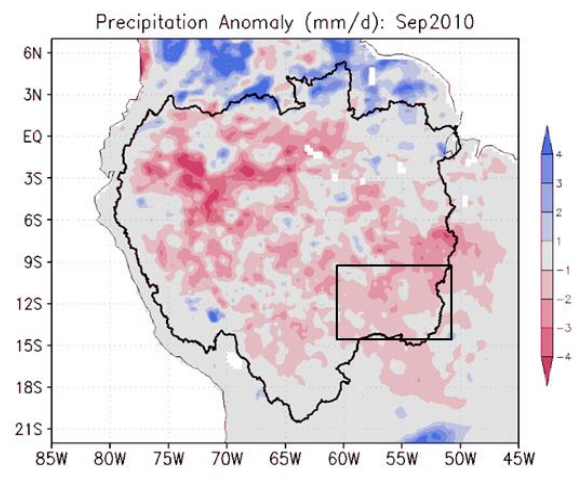

(a)

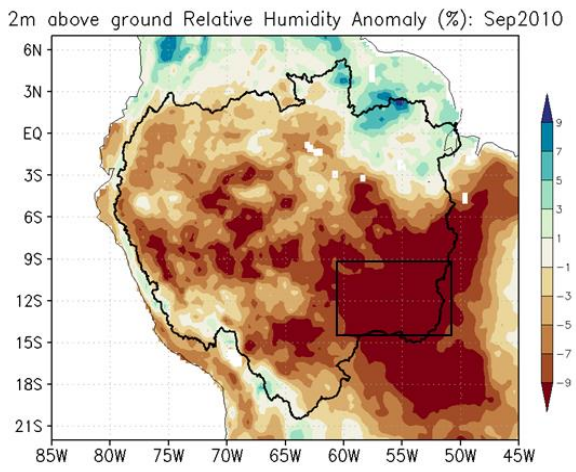

(c)

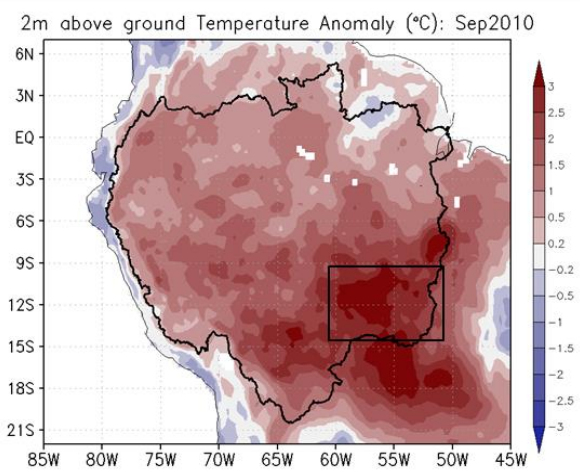

(b)

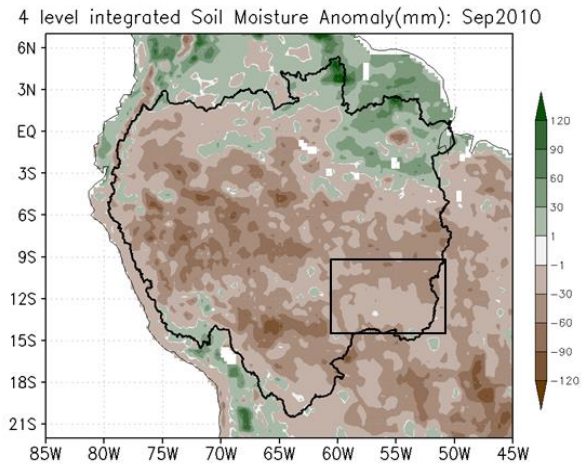

(d)

Figure 4. Same as in Figure 3, except for September 2010.

\section{Conclusions}

In both events, the SRDAS product could identify the location of the drought, according to past studies, as well as how extreme they were. According with previous studies, SRDAS data show that the 2005 drought affected mainly the western Amazon Basin, while in 2010 it was affected again together with the southeast sector. Our analysis suggests that the occurrence and combination of extreme values of meteorological variables such as humidity, soil moisture and temperature also occurs in specific geographic locations, whereas the western Amazon Basin sits on the edge of the water deficit and temperature surplus in 2005 (2010), the decreasing in precipitation was the main factor in the southeast sector during 2010. The highest anomaly values in SRDAS depicted the epicenters of the droughts that occurred in the Amazon basin, using near-surface and surface variables, revealing that the teleconnections due to ENSO and anomalies of the North Atlantic SST might be kept in the regional inner domain from the large-scale features of a global reanalysis.

Acknowledgments: The research was supported by FAPESP/FCT Project Brazilian Fire-Land-Atmosphere System (2015/01389-4) and in part funded though FAPERJ awards 111.556/2011 and 111.381/2014.

Author Contributions: Beatriz Garcia wrote the first draft of the paper; Beatriz Garcia and Renata Libonati analyzed the data and/or products; Renata Libonati and Ana Nunes elaborated the paper; and Ana Nunes developed the product, performed the numerical experiment, and contributed to the analyses.

Conflicts of Interest: The authors declare no conflict of interest. The founding sponsors had no role in the design of the study; in the collection, analyses, or interpretation of data; in the writing of the manuscript, and in the decision to publish the results. 
The 1st International Electronic Conference on Hydrological Cycle (CHyCle-2017), 12 -16 November 2017;

Sciforum Electronic Conference Series, Vol. 1, 2017

\section{References}

1. Meggers, B. J. Archeological evidence for the impact of MegaNino events on Amazonia during the past two millennia. Climate Change 1994, 28, 321-328. doi: 10.1007/BF01104077

2. Marengo, J. A. Interannual variability of surface climate in the Amazon basin. Int. J. Climatol. 1992, 12, 853863.

3. Marengo, J. A. Interdecadal variability and trends in rainfall in the Amazon basin. Theor. Appl. Climatol. 2004, 78, 79-96.

4. Marengo, J. A. et al. The drought of Amazonia in 2005. J. Climate 2008, 21, 495-516.

5. Marengo, J. A.; Tomasella, J.; Alves, L. M.; Soares, W. R.; Rodriguez, D. A. The drought of 2010 in the context of historical droughts in the Amazon region. Geophys. Res. Lett. 2011, 38, L12703, doi:10.1029/2011GL047436.

6. Panisset, J. S. et al., Contrasting patterns of the extreme drought episodes of 2005, 2010 and 2015 in the Amazon Basin. Int. J. Climatol. 2017

7. Nunes, A. M. B. Satellite-enhanced dynamical downscaling for the analysis of extreme events. J. Geophys. Res. 2016, 121, 10617-10636.

(C) 2017 by the authors; licensee MDPI, Basel, Switzerland. This article is an open access article distributed under the terms and conditions of the Creative Commons by Attribution (CC-BY) license (http://creativecommons.org/licenses/by/4.0/). 